\title{
An Interview with Professor Thomas J. Laffey
}

\author{
GARY MCGUIRE
}

\section{INTRODUCTION}

On the occasion of his 65 th birthday I conducted an informal interview with Tom, to gather some memories and stories. This is the second recorded interview with Tom; the first can be found online.

\section{BACKGROUND}

GMG: From what age did you get interested in mathematics?

TL: I come from a background with no tradition in education. My parents were farmers in County Mayo. Very few members of the family had gone to second level education. My father and mother thought education was a way of getting away from farming, so they encouraged all their children in that respect. I remember a neighbour of mine was interested in reading, and had some books. People around there were quite poor and books were not common, so this neighbour had some influence on me. We lived near the MayoGalway border. I remember the man who ran the local post office was a (Gaelic) football fanatic. When Mayo got knocked out of the championship before Galway, as usually happened, he would switch his support to Galway.

After primary school my parents hoped I would get a scholarship for secondary school. During my first year in secondary school I got the scholarship, which supported me for the remainder of my secondary school days. During that first year I was actually put into second year classes, which helped me get the scholarship. At the end of third year I did the Inter Cert, and I did very well, particularly in mathematics and latin. Because the principal felt I was a bit young to start the Leaving Cert, and there was no transition year at that time, the principal told me to do the Inter Cert again. So I did the Inter Cert a second time, which involved different books and plays 
in subjects like English. Then we got a new school principal, who was more interested in encouraging students to go to third level. I think he came from O'Connell's school in Dublin. He encouraged me to do honours maths in the Leaving Cert. This was unusual at the time, only a small number of schools offered honours maths. I was the first student ever from my school to do honours maths in the Leaving Cert.

The new principal gave me a lot of books from the school library. These books were very old, like Crystal's algebra and Hall and Stevens' Geometry. They had been in the school since the school was founded. He also arranged for a brother who was an honours maths teacher to come on five Saturdays over the two years, to give me a few classes. Mostly I learnt the material myself from reading the books. It taught me that having several sources is a useful thing, because sometimes one book has a very nice treatment of one thing, whereas it's a different book that has the best treatment of the next result.

I also practiced on the past papers, a bit like students do now. During school time, I was the only one doing honours maths so during pass maths class the teacher used to make me do the problems on the board while he went off and took a break. There was always the threat of him coming back, so there were no discipline problems.

GMG: So is it fair to say you are self-taught?

TL: Yes, you could say that, at that level, in mathematics and physics anyway. One new thing for me was learning mathematics through English, because all subjects were taught through Irish at that time. Because the books were written in English, I was now learning mathematics through English. This had a funny consequence later at UCG, when I was a senior undergraduate. At that time the head of the Commerce faculty was a gaelgóir and insisted that all subjects were taught and examined through Irish. First year students had to do maths. During the actual exam, some people (usually senior undergraduates or MSc students) had to be available to answer student queries and orally translate Irish phrases in the paper for students who didn't understand the Irish. I was one of the few students who knew the technical terms in both English and Irish, because of reading the books in English and being taught through Irish. 
I was also self-taught in physics, because the teacher concentrated more on experiments but I was more interested in the theoretical parts.

GMG: It's quite an achievement to learn the honours maths syllabus by yourself, and obtain one of the top marks in the country. If that principal had not encouraged you to do honours maths, where would you be now?

TL: Perhaps I would have become a primary school teacher, because that was a realistic option at the time. It was something you could do without having the money.

GMG: You went on to university then.

TL: My parents could not have afforded to send me to university. I ended up getting a state scholarship to university, and I went to UCG, which is now named NUI Galway. There were around 20 of those scholarships at the time, over the whole country, and usually they went to students from the top fee-paying schools. They were not dependent on the income of the parents. My principal was congratulated because no-one from a school like mine had won a state scholarship before. I also got a Mayo county council scholarship, of which there were two, and these were dependent on parents income. However the state scholarship was more lucrative, so I took that one.

Maths and classics counted slightly more towards the state scholarship than other subjects, 600 as opposed to 400 for other subjects. I was able to get very high marks in those two subjects, so this helped me get the state scholarship. Latin at that time was quite technical and mathematical, in a way, so it suited me. You had to make everything grammatically correct, and there were certain rules that had to be obeyed. They gave certain rhythms, various numbers of shorts and longs. Recently I heard that the old testament when spoken in Aramaic has this kind of a rhythm to it. Since students could score close to full marks in maths and latin, being good in those helped win the scholarship. Many of the scholars studied maths, but also some went into classics, one example being Tom Mitchell, the former provost of TCD. He was a few years ahead of me. 


\section{SeCondary School Matters}

GMG: You have been been involved in the BT Young Scientists exhibition for some years now, as a reviewer and as a judge. What are your thoughts on it?

TL: It generates great excitement for the children. It teaches them that academic subjects can be exciting. It seems that children do a lot of memorization in school, but unfortunately they also do this in mathematics. So one of the main benefits is that secondary school students get a feeling for what it is like to find out something for themselves, and they may discover that the actual process of discovery is exciting and enjoyable. This is probably more true for group projects than individual projects - more excitement is generated.

It is also important for the country, because the winner competes in a European competition and some international competitions. This gives important visibility to Ireland. For example, this year's individual winner has won prizes sponsored by the American Mathematical Society and the Indian Mathematical Society at the Intel Science Talent Search in the USA.

Mathematics projects have been both group and individual. The number of mathematics projects was extremely small for a period in the 1990s, and there was no mathematician on the judges panel then. If a mathematics project was a contender for a prize, they used to call in a mathematician to be sure of the quality (for the reputation of the competition and the sponsors). At that time I was normally the person who was called. That was before the year 2000, approximately. I have been a judge since about 2000. Fergus Gaines was a judge back in the 1980s.

GMG: Tony Scott, who is in Experimental Physics in UCD, was a founder of the Young Scientists competition I believe.

TL: Yes, it was started by Tony Scott and the late Fr. Tom Burke in the 1960s, and they obtained sponsorship from Aer Lingus for about the first 30 years. What happened was that Fr. Tom Burke visited Los Alamos lab to do research on sabbatical, and he invited Tony Scott to visit him there for the summer, as they did research together. He asked Tony to come early to see a science exhibition they had there, and then he and Tony had the idea that they might run such a thing in Ireland. That's how it started. 
GMG: And I believe that one year a student entered a mathematics project that would have won him a Fields medal?

TL: Yes, a student entered a project claiming to have proved the conjecture about primes in arithmetic progressions, a result that was recently proved by Green and Tao. Not only that, he also claimed to have proved a conjecture of Hardy and Littlewood, that $\pi(x+y) \leq$ $\pi(x)+\pi(y)$. Both proofs were incorrect, however the project was very good and showed talent. He had a number of correct lemmas that were quite sophisticated, and he ended up winning the prize. I recall being asked whether these results would be publishable, if they were correct. I replied that not only were they publishable, they would win him a Fields medal!

GMG: Were you involved the year that Sarah Flannery won the Young Scientists competition with her cryptography project?

TL: No, in fact I was in Portugal that year doing some research. I recall being shown a Portuguese newspaper whose front page headline was about an Irish genius who was going to be a millionaire with a new encryption system. A footnote on that article thanked Le Monde for allowing them to use their article, and translate it.

The consultant for that project was a visitor in Trinity College, I believe, who said it would be very good work if correct, and could not find any mistakes at the time. Her father, David Flannery, asked me to go over it before Sarah entered the European Young Scientists competition. I noticed that you could break it without much trouble, because she had a $2 \times 2$ non-derogatory matrix $A$ and another matrix $B$ that commuted with $A$. If you apply the theorem that $B$ must be a polynomial in $A$, you can break the system. I wrote to David Flannery and told him this, he came up to Dublin and we talked about it. In the European competition Sarah also presented the attack.

GMG: I understand that politicians played a role in the first participation of Ireland in the International Mathematical Olympiad. Could you tell me about the background to that?

TL: Ireland first participated in 1988, as it eventually turned out. That year the event was held in Australia. But let's go back a bit. In fact, it all began with Con O Caoimh, a secondary school teacher in 
Cork who later went into the Department of Education and became chief inspector for mathematics. In the 1970s he ran a competition in Cork with tricky maths problems. He got the best students to take part in the American high school mathematics competition, long distance. Finbarr Holland in UCC thought it would be great to run such a competition nationwide. He discussed this with me, and I said I would be happy to help out. Fergus Gaines was also very supportive. Starting in 1978 the three of us ran that competition. Subsequently we always talked about having Ireland compete in the International Mathematical Olympiad (IMO), because you would hear about this a lot at conferences and so on. People would be talking about a great mathematician Joe Bloggs, and they would say that Joe represented Russia or whatever country he came from in the IMO when he was younger, and won a gold medal. So we thought it would be good for mathematics in Ireland if we entered the IMO.

Moving into the 1980s then, the country was in recession and times were hard. We felt our only hope was to wait until the IMO was being held in a nearby country. It was due to be held in Germany in 1989, which we could have travelled to by boat and train. Flying was out of the question, it was too expensive.

Completely out of the blue, a man named Peter O'Halloran, who was the the chief organiser of the IMO to be held in Australia in 1988, wrote a letter which ended up on Finbarr Holland's desk somehow. It was originally written to the government or the academy, I think. Anyway, O'Halloran said that he had managed to get the Australian government to name the IMO as an official event of the Australian bicentennial, to be held in 1988. You see, O'Halloran was in a university in Canberra, which is a small town consisting mainly of politicians and academics at the two universities there. The academics there have great access to the politicians. So O'Halloran was able to get great political and financial support for the IMO, he had great people skills. The point is that O'Halloran said it was very important that Ireland participate in the IMO in Australia, because of all the historical and cultural links between the two countries.

Peter O'Halloran managed to get the Australian ambassador to Ireland on board, and asked him to tell every Irish minister he met that Ireland should particiapte in the IMO. The Irish Minister for Education at the time was Patrick Cooney, from Athlone, who had replaced Gemma Hussey in 1986. It turned out that he was a good 
friend of the Australian ambassador! Peter Barry was also contacted, he was Minister for Foreign Affairs at that time, in Garrett Fitzgerald's Fine Gael-Labour government. So we met both these ministers and the ambassador in one week. They were worried about the finances, but nevertheless they agreed to support an Irish team to go to the IMO in Australia. They also set up a committee, which still exists, to regulate Ireland's participation in the IMO in future years. The first such committee had myself, Finbarr Holland, Con O Caoimh, and Bill Nolan from the Department of Foreign Affairs.

However, there was then a change of government in 1987 when Charlie Haughey became Taoiseach. Immediately after the election, financial cutbacks came to the fore, and we feared that the IMO funding would be lost. Luckily, Peter O'Halloran had convinced the Australian Minister of Culture that it was important for Ireland to participate in the IMO, and this Minister was on an opportune visit to Dublin. He was speaking at a dinner where Brian Lenihan (Minister for Foreign Affairs after Peter Barry) was present. During his speech he said that Australia wanted an Irish team to take part in the IMO! Coming from outside, this was very powerful. It all worked very well and that's how our politicians came to support the IMO. The new government agreed to send an observer to the IMO in Cuba in 1987, to see how it all worked, and Finbarr went there.

It is curious that Ireland was in dire straits economically at the time, and a trip to Australia was about as expensive as you could get, maybe 1300 pounds, and yet it happened. It's probably still the most expensive IMO we have ever participated in!

GMG: Looking back, after 20 years of participation, do think it has been good for Ireland to participate in the IMO?

TL: Yes, I think it has. I remember one time a teacher told me that the great thing about olympiad training is that his best students have actually met questions that they don't immediately know the answer to. Those students are used to knowing the answer to every question that is asked in school, and knowing it immediately. So for these students to actually struggle with a question, to meet a question that challenges them, he felt it was a good thing for them and stopped them boasting.

We still find it difficult to get people to come for the training, but for those who come it is very beneficial. 
I think it plays an important role for the country, in that it ensures visibility. Every European country enters a team, and just about every so-called "advanced" country is involved.

Siddartha Sen once said to me that the olympiad training is having a curious social consequence. One finds that many of the top students know each other from olympiad training, and this includes students from all universities and all subjects! The students who have participated in olympiad training tend to be determined and hard-working people, and go on to be top of their class in university.

From the point of view of winning medals, we are not in the professional leagues. We win some medals, I think we have won about 8 so far. We have been successful with setting questions, in that we have had four questions appear on the actual IMO exam.

GMG: Have you participated much on committees related to secondary school mathematics?

TL: Yes, back in the late 1960s and early 1970s, there was a national committee formed to discuss and implement a change of syllabus this was the era of so-called "new mathematics." Professor Gormley, who was head of department in UCD, was on the committee, he was the NUI rep. After he died in 1973 I was his replacement for a few years on the review committee. At that time there was a lot of discussion about the geometry, and what should be on the higher level syllabus. There were a lot of teachers reps. The university people were quite conservative and did not show the same excitement as the teachers for new mathematics. Within the academic community of mathematicians opinion was divided. I remember Stephen O'Brien who was at UCD was in favour of it, and Con O Caoimh whom I mentioned earlier was also in favour of it. Professor Timoney, Professor Gormley, David Lewis and myself were more sceptical. The teachers put this down to us being in a university environment, and not having to go in and teach thirty 15 -year olds every day. The main university contribution was that the influence of very non-intuitive geometry was diminished from the first draft, which I was happy about.

GMG: What other suggestions did you make?

TL: I remember for example that the university people were in support of having a lot of material on solvability of linear systems of 
equations. On the other hand, we suggested that finite group theory be dropped because the amount covered in school was so little, and in university we start from scratch anyway. However the teachers organizations sent word back that they did not want linear systems of equations, but they did want the group theory. I think this reflected the fact that the group theory scope was so limited, so the number of questions that could be asked was very small, whereas there would be huge scope for different questions on linear systems of equations.

One thing teachers were anxious to have was that the exam adhere to the syllabus very strictly. It was claimed that Con O Caoimh used to use the exam to move the syllabus in a direction he thought was beneficial. For example, he might put in a question with a $2 \times 2$ matrix $A$, and he would ask students to find a number $\lambda$ and numbers $x$ and $y$ so that $A$ times the vector $(x y)$ is equal to $\lambda$ times $(x y)$. This can of course be solved by writing down the equations and bashing it out. There would be complaints that eigenvalues and eigenvectors were not on the syllabus, but this was his way of introducing it. The top schools would then learn eigenvalues and eigenvectors for the next years exam, because their teacher would prepare them for it. In this way the syllabus had grown a little bit. The teachers unions used to object to this, because it was not adhering to the syllabus.

There used to be a university representative on the Department of Education Inter Cert advisory board, but this had stopped by the 1970s.

GMG: I gather there was once a stolen Leaving Cert exam paper.

TL: In the 1990s the Department of Education used to send copies of the Leaving Cert exam to the universities for approval. This is because the exam was acting as a matriculation exam, after the NUI matriculation exam was abolished. So for some years I had to approve the draft copy and make comments, and I made a trip to the Department of Education. I was the NUI representative delegated to get the copy of the Leaving cert exam in advance.

One year a different NUI representative kept his copy of the paper in the small safe in his university. A thief broke in over a weekend and took the safe away. It was later found elsewhere on campus and it had been broken into. The contents had disappeared. I doubt whether the thief was interested in reading mathematics, but anyway, the exam was considered to be compromised and had to be set again. 
It was not the fault of the NUI representative of course, he had taken every precaution.

I also used to sit on the Mathematics committee of the Royal Irish Academy. The RIA used to have three committees, two for mathematics and one for mechanics, but now they are merged into one, a committee for mathematical science. One job of the committee is to suggest names for the Hamilton lecture, which takes place each year on 16 October. This year (2009) we will have Zelmanov speaking.

\section{Your Mathematical Career}

GMG: You embarked on your mathematical career in Sussex, where you received your Ph.D. under Ledermann.

TL: The maths department in Galway where I did my undergraduate degree, was headed by Sean Tobin. We got a very strong training in algebra, probably the strongest in the country at that time (the 1960s). It was different in Cork where the strength was in analysis. Because of Sean Tobin, if you did your degree in Galway and you wanted to do a $\mathrm{PhD}$, you went off somewhere to do a $\mathrm{PhD}$ in group theory. A number of people did that. Tobin himself was a student of Higman. Students used to enjoy the group theory, it was elegant and also tricky stuff. Students used to enjoy the trickiness of it. Well, some students anyway!

After I did the masters in Galway, I was an assistant lecturer there for a year. During that year I was thinking of doing further postgraduate work, and I needed funding. I wrote to Walter Ledermann in Sussex, and he invited me for an interview. I got the train to Dublin, the boat to Holyhead and the train to London and then to Brighton. I met Ledermann and I got an offer of a grant from Sussex.

I also wrote to Philip Hall in Cambridge, because I had heard his name in lectures from Sean Tobin when he discussed Hall subgroups and things. Hall wrote back to me saying he would nominate me for a Gulbenkian fellowship. I had never heard of a Gulbenkian fellowship before, but anyway he said he would nominate me. However the decision wouldn't be made for 3 months. I did not know if I would get that fellowship, so I accepted the offer from Ledermann. Had I known the system in Cambridge, and the status of Philip Hall, I would have known that whoever Hall nominated was very likely to get that fellowship. I'm very sorry I didn't keep that letter from 
Hall. The letter I got from him talked about all the things in group theory that we could work on, and it was very interesting.

GMG: How were things at Sussex?

TL: It was very nice at Sussex, and Ledermann was a very nice person to work with. I was the only finite group theorist, besides Ledermann, but there were some infinite group theorists like Dunwoody. Very soon after going to Sussex there was a Fulbright fellow there from America named Bob Bumcrot, who was joining in the algebra seminars we had every week. He had done his PhD in finite geometries with Marshall Hall. I remember Bumcrot being a bit discouraging about finite group theory, because he said it was so difficult. His reason for thinking this was as follows. He thought that Marshall Hall was the greatest genius he could ever imagine. He used to talk about how Marshall Hall could fill up the blackboard with equations and then start proving things on the spot. But then Marshall Hall came back from a conference on finite group theory once and told Bumcrot that he had met Thompson and people like that, and that they were so clever and how he couldn't imagine anyone being as clever as those guys. So I didn't find this very encouraging as I was starting out in finite group theory! He kept talking about how clever all these guys were.

I felt really well off at Sussex at that time, because the grant was very good. I didn't have to pay any tax on that grant, and I was paid almost the same as the lecturers after you deducted tax from their pay. Sussex was a new university, and I was one of the first $\mathrm{PhD}$ graduates from there in mathematics.

GMG: What mathematicians have been a big influence on you?

TL: While I was in Sussex, E.C. Dade was visiting London from Caltech for six months and he was giving a course on representation theory. Ledermann arranged for me to meet him and attend that course, and that's really where I learnt representation theory. Dade used to give two hour lectures non-stop, going like lightning.

At one stage Ledermann was very worried, because he had met Fröhlich who told him that Dade's lectures were difficult to understand. So Ledermann came in to reassure me that I shouldn't worry if I found the lectures very hard. 
Then Ledermann discovered that Feit was coming to Warwick to visit. He arranged for me to meet with Feit and to discuss what I might work on. So I did that and we talked about various problems. I met Feit about 20 years later, and he remembered having met me that time in Warwick, which I was surprised about.

Olga Taussky was a very big influence on me. When I came to UCD in 1968 there was virtually no algebra here, the only person doing algebra was Fergus Gaines. David Lewis was more interested in geometry then. I decided I would learn the matrix theory that Fergus Gaines knew, and then I could work with him. He had done his PhD at Caltech under Olga Taussky. So I spent some time learning matrix theory, which also involves learning some ring theory.

I spent the year 1972-73 in Northern Illinois University, west of Chicago. John Lindsey was there, he was a student of Feit and he was also a Putnam fellow. He is one of these people who solves most of the American Mathematical Monthly problems. Also Selfridge was there, he was in number theory, as head of department. And Harvey Blau and Henry Leonard were there, who were group theorists. There were a few visitors there that year, like John Brilhart. Paul Erdös visited for a term that year. Derrick Lehmer was there, he was interested in computation and prime numbers, like Brilhart. There was also a very active seminar in semigroups, led by McFadden and McAlistair, both originally from Northern Ireland.

I remember that year there was a guy working in differential equations named Zettl who used to come around to the algebraists asking matrix theory questions that arose in his work. To my surprise, I found that I knew more matrix theory than most of the algebraists there, and I was able to answer some of this questions. I started to think more about matrix theory at that stage, and gradually moved into matrix theory.

To go back to Olga Taussky, I started to look at questions that Olga has asked, which Fergus told me about. I used to write to her quite a bit. She was motivated by questions in matrix theory and number theory, so she had a big influence on me and I spent a lot of time on that stuff. One thing about Olga Taussky was that she knew everybody. So if I was at a meeting and she was there, she would introduce me to all these people and tell them what I was doing. I remember one meeting in Pittsburgh where I met Harold Stark and Peter Lax. She was great like that, for introducing people around the place. She knew all the big name people. I remember one time 
I was in Caltech, and John and Olga had Charles Fefferman and his wife and me for dinner. I knew her husband John Todd well, but not very much mathematically. His niece Jenny teaches in UCD.

I got more into linear algebra and matrix theory from about 1980 onwards, which led me to non-negative matrices and that's a topic I have been interested in for about the last ten years.

\section{Mathematics In General}

GMG: How do you think mathematics has changed as we moved from the 20th to the 21st century?

TL: One of the big changes that has happened since the 1960s is the development of algorithmic mathematics, and applications of mathematics. One was always aware of applications of differential equations, but the applications of discrete mathematics has tremendously influenced mathematics over the last twenty years. Bourbaki is dead now. It's more old fashioned than the mathematics of 100 years ago, in a sense. There was obviously motivation there, but they didn't stress the motivation, they derived mathematics from the axioms. We were trained in this way in the sixties, we were trained to do the definition and theorem and proof. We didn't get the intuition when we were trained, it wasn't considered the right thing to do. Also there was no reason for bringing in applications. The idea that applications might actually help you or give you an insight was not at all emphasized in pure mathematics. The idea was that pure mathematics was superior in the sense that it was totally rigorous. That whole world has changed. There is an experimental side to mathematics now that wasn't present when I was young. You can do lots of experiments to see if an equation has a solution, or something like that.

So I've seen a big change in the philosophy of the subject. The biggest change is that there is an interest in applications of the subject, and that is happening at every level of the subject. Even at the Fields medal level, people like Terry Tao are interested in applications of their work. That was not true 30 or 40 years ago.

Another aspect of mathematics that has changed is its unification, the development of machinery that unifies algebra and analysis and number theory. 
There are also a lot more people involved in mathematics research now, there are a lot more papers being published each year.

Another thing I find interesting is the success there has been in solving famous problems. In the last forty or so years, a number of problems have been solved like the Poincaré conjecture and Fermat's Last Theorem. There are also other big results, like the classification of finite simple groups, which as far as anybody knows is complete. The easiest ones to understand are problems in number theory, questions to do with the distribution of primes. And there are totally new areas like coding theory. I remember the first time I heard about that was in a talk by Thompson, and he was talking about the projective plane of order 10 existence question, and he had derived properties of the code. He also had proved things about the automorphism group of the code. Eventually the computer was able to complete it, using the work of Thompson and others. But that's a new kind of thing, algebra being applied. Another lecture I remember is one at the BMC by Conway who talked about Leech lattices and Golay codes.

One area I would like to have known more about at an earlier stage in my life is engineering, and how these things, particularly algebraic things, are used in engineering. In the 1990s there were articles in several journals about how algebra was being used, how things like finite fields and difference equations were now useful. We discussed offering coding theory and finite fields to the engineering students here.

GMG: How has mathematics changed in Ireland?

TL: There are a lot more people now doing mathematics in Ireland. The amount of research in the country has enormously increased, even in the last ten years. When I started, there was very little research done in Ireland. Around 1970, say, there were a couple of people doing some research in TCD. In Galway there was some research in group theory, which is the area they focused on. Cork had some research in complex analysis. There were a few people getting research off the ground in UCD. Now this picture has changed enormously.

GMG: What do you think of the funding situation in Ireland? 
TL: One of the problems facing mathematics is to get more people to do it. Having money to fund people to do $\mathrm{PhDs}$ is a big change that happened in Ireland, and this is good for getting people to study mathematics. It is good for academic staff here to have $\mathrm{PhD}$ students around - in the early days we didn't have that. We didn't have money to support students, except for the little money they could get from teaching. Now we have more funding. It's great to have postdocs and $\mathrm{PhD}$ students around our universities. It's great to be able to bring people in from abroad as well. I think we should continue to send some students abroad for their PhD. I do think that our best students should get some experience abroad, not necessarily at $\mathrm{PhD}$ level, it could be at postdoc level. It's good to go to a big centre abroad. Before, this was forced on us; the only way we could get funding was to go abroad, so most people went to the US for their PhD.

I do worry sometimes about how all these PhDs will get jobs. The theory is that Ireland will develop an economy and an industry that can hire PhDs in mathematics, like the US has. The present economic situation is a bit of a setback to that. In some places, like in Toronto for example, they prefer to hire $\mathrm{PhDs}$ in mathematics to work in their financial centre. In Germany some Deutsche Bank people said that the maths $\mathrm{PhDs}$ were the most useful people they hired, and mathematicians have been using that there to get more people to study maths. Apparently it has been successful there.

GMG: Tom, thank you very much.

Gary McGuire,

School of Mathematical Sciences,

University College Dublin,

Dublin 4, Ireland

gary.mcguire@ucd.ie

Received on 26 June 2009. 